\title{
ROLE OF BODY MASS INDEX AND ANTENATAL CARE IN MODE OF DELIVERY, BIRTH WEIGHT AND HAEMOGLOBIN AT TERM
}

\author{
Dattatraya Gopalghare ${ }^{1}$, Renu Pimpale², Pranali Ghuge ${ }^{3}$, Patit Paban Panigrahi ${ }^{4}$
}

\section{HOW TO CITE THIS ARTICLE:}

Dattatraya Gopalghare, Renu Pimpale, Pranali Ghuge, Patit Paban Panigrahi. "Role of Body Mass Index and Antenatal Care in Mode of Delivery, Birth Weight and Haemoglobin at Term". Journal of Evolution of Medical and Dental Sciences 2014; Vol. 3, Issue 46, September 22; Page: 11170-11176,

DOI: $10.14260 /$ jemds/2014/3457

ABSTRACT: BACKGROUND: The current maternal mortality rate of India is 212/100000 live births whereas the country's millennium development goal in this respect is $109 / 100000$ live births by 2015. Although the progress has been made, the actual target remains far from sight. A step to achieve this goal would be to identify the factors affecting maternal mortality \& curtail them. AIMS AND OBJECTIVE: To see the impact of BMI and number of ANC visits on mode of delivery baby weight and anaemia at term. So as to ensure that throughout pregnancy, the mother will have good health \& that every pregnancy may culminate in healthy mother \& healthy baby. STUDY SETTING: A tertiary care hospital attached to MIMER Medical College, Talegaon Dabhade, Pune. STUDY DESIGN: Community Based Cross-Sectional Study. MATERIALS AND METHODS: A suitable proforma was designed. Study design consisted of 342 pregnant women with singleton pregnancies. Inclusion criteria: Primigravida or multigravida with gestational age of $>34$ weeks \& singleton pregnancies. DATA ANALYSIS AND STATISTICAL TESTS: Rates, Ratios, Proportions and Chi-square tests. CONCLUSION: BMI is a good indicator of nutrition in pregnant women. Females with good BMI has less chances of having LBW baby \& have less chances of developing anaemia. Good amount of antenatal care leads to decrease in maternal \& foetal mortality \& morbidity. Though a minimum number of 3 visits are suggested, the study proves, minimum number of 5 visits is essential to decrease the LBW \& anaemia incidence in mothers.

KEYWORDS: Body mass index, antenatal care, delivery, birth weight, haemoglobin.

INTRODUCTION: The current maternal mortality rate of India is 212/100000 live births whereas the country's millennium development goal in this respect is 109/100000 live births by 2015. Although the progress has been made, the actual target remains far from sight. A step to achieve this goal would be to identify the factors affecting maternal mortality \& curtail them. Various studies have been carried out to identify such factors.

One of these factors is nourishment of the female. Obesity is considered as a risk factor ${ }^{1}$ in developed countries. However in most parts of India, especially the rural areas, under nutrition are more of a risk factor than obesity. Hence we have considered nutritional status of mother as factor in our study. Anthropometry is a good tool to measure the nutritional status of an individual. Body mass index is one such anthropometric tool useful in determining nutritional status of an individual. It is calculated with the help of height \& weight of an individual.

Most of the studies have considered the pre-pregnancy $\mathrm{BMI}^{2} \&$ weight gain during pregnancy. They have related it with preterm labour mode of delivery infectious complications in preterm 3 . Only few of the studies have considered BMI of the mother at term. This study has considered the BMI at term \& its effects on outcome of pregnancy by comparing it with various parameters. 
Other important factors considered in this study are antenatal care \& age of mother.

Antenatal care received by the mother is determined by the number of ANC visits by the pregnant female throughout the pregnancy period. It is considered that it helps in reducing the preventable complications. This study has considered the factor to see its effects on outcome of pregnancy.

Age of the female is also included in the study as both elderly as well as younger females have different complications in pregnancy.

Various parameters used in determining the outcome of pregnancy are birth weight of the baby, mode of delivery \& $\mathrm{Hb}$ at term. Low birth weight may lead to physical \& mental retardation, LSCS has many complications \& PPH in anaemia may cause shock \& also death of mother. All these parameters directly or indirectly add to the maternal morbidity \& mortality. Hence are considered in this study.

AIMS AND OBJECTIVE: To find association between percentage of LBW, LSCS \& anaemic mothers with different ranges of BMI.

To find association between percentage of LBW, LSCS \& anaemic mothers with number of ANC visits.

To ensure that throughout pregnancy, the mother will have good health \& that every pregnancy may culminate in healthy mother \& healthy baby.

MATERIAL AND METHODS: It was a cross sectional study carried out in a tertiary care hospital in a rural area. The females who delivered in this hospital during the period from october-2011 to December-2011 were considered under the study.

Study design consisted of 342 pregnant women with singleton pregnancies.

Inclusion Criteria: Primigravida or multigravida with gestational age of $>34$ weeks \& singleton pregnancies.

Exclusion Criteria: Pregnancies of $<34$ weeks gestation \& multi-gestational pregnancies, as they may itself affect the weight of female, ultimately affecting the BMI.

\section{Variables under Study:}

- Height of female.

- Weight at the time of delivery.

- Haemoglobin at the time of delivery.

- Birth weight of the baby.

- Mode of delivery.

- Number of ANC visits.

The records were used for data collection.

BMI was calculated using the formula =weight $(\mathrm{kg}) /$ height (metre). ${ }^{2}$

Low birth weight was considered $<2.5 \mathrm{~kg}$.

Low haemoglobin level was considered below $9 \mathrm{gm} / \mathrm{dl}$. 
Number of ANC visits by the female throughout her pregnancy period depicted the antenatal care received by her. It was found from the OPD paper the female submitted to the records.

OBSERVATIONS: 342 patients satisfying the inclusion criteria were included in the study.

Out of these there were total 138 LSCS, 103 LBW \& 51 anaemic.

BMI of all the females was calculated \& divided into 4 groups in increasing order. Then number of LSCS, LBW's \& anaemic females was calculated in each group. Chi square test was applied to find any significant association between BMI, LSCS rate, LBW rate \& anaemia at term.

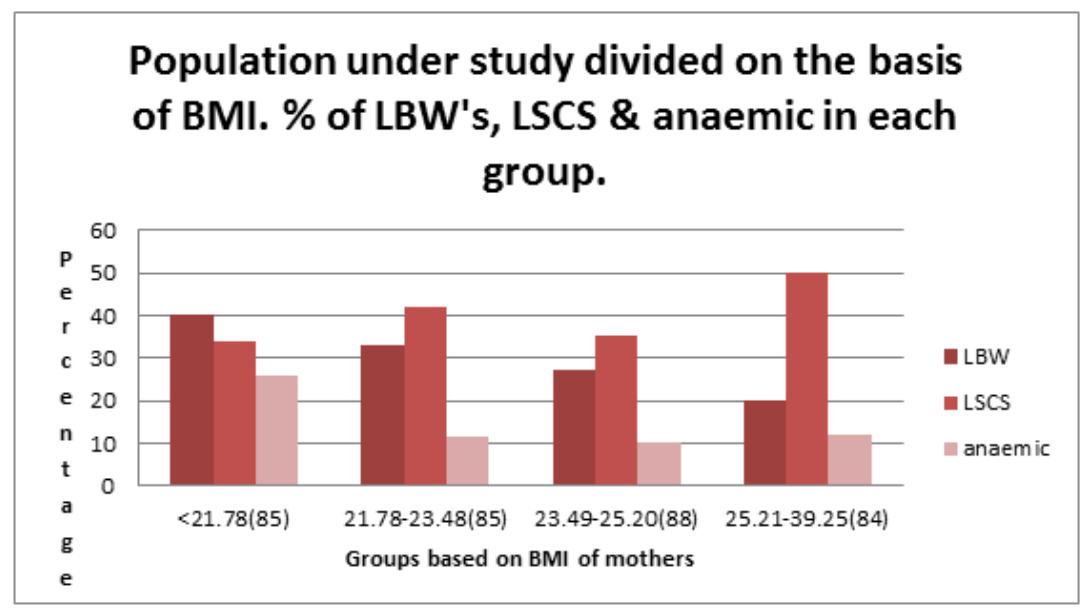

\begin{tabular}{|c|c|c|}
\hline BMI range & LBW & $\mathbf{\%}$ \\
\hline$<21.78(85)$ & 34 & 40 \\
\hline $21.78-23.49(85)$ & 28 & 32.94 \\
\hline $23.49-25.21(88)$ & 24 & 27.27 \\
\hline$>25.21(84)$ & 17 & 20.23 \\
\hline Total & $\mathbf{1 0 3}$ & $\mathbf{2 0 . 2 3}$ \\
\hline Chi square & 5.23 & P value-0.14 \\
\hline
\end{tabular}

Table 1: Distribution of low birth weight babies in different BMI groups

A trend was seen, with increasing BMI, the LBW's decreased. On statistical analysis, it was found to be marginally significant.

\begin{tabular}{|c|c|c|}
\hline BMI range & LSCS & \% \\
\hline$<21.78(85)$ & 29 & 34.11 \\
\hline $21.78-23.49(85)$ & 36 & 41.86 \\
\hline $23.49-25.21(88)$ & 31 & 35.22 \\
\hline$>25.21(84)$ & 42 & 50 \\
\hline Total & $\mathbf{1 3 8}$ & $\mathbf{4 0 . 3 5}$ \\
\hline Chi square & 3.42 & P value- 0.32 \\
\hline
\end{tabular}

Table 2: Percentage of LSCS in different BMI groups 
On statistical analysis no significant relation was seen between BMI \& incidence of LSCS. In cases with BMI > 25.21 LSCS rate was 50\%.

\begin{tabular}{|c|c|c|}
\hline \multicolumn{1}{|c|}{ BMI range } & anaemic & $\mathbf{\%}$ \\
\hline$<21.78(85)$ & 22 & 25.88 \\
\hline $21.78-23.49(85)$ & 10 & 11.76 \\
\hline $23.49-25.21(88)$ & 09 & 10.22 \\
\hline$>25.21(84)$ & 10 & 12 \\
\hline Total & $\mathbf{5 1}$ & $\mathbf{1 4 . 9 1}$ \\
\hline Chi square & 8.48 & P value- 0.03 \\
\hline
\end{tabular}

\section{Table 3: Percentage of anaemia in different BMI groups}

A statistically significant relationship was found between Increasing BMI \& decrease in anaemic mothers.

Now the number of LBW's, LSCS \& anaemic mothers were divided into 4 groups on the basis of number of ANC visits. They were statistically analyzed, by applying Chi square test, to find the significant association.

\begin{tabular}{|c|c|c|}
\hline No. of ANC visits & LSCS & \% \\
\hline$<3$ & 22 & 26.50 \\
\hline 3 & 37 & 46.67 \\
\hline 4 & 18 & 28.12 \\
\hline $5-9$ & 61 & 53.50 \\
\hline Total & $\mathbf{1 3 8}$ & $\mathbf{4 0 . 3 5}$ \\
\hline Chi square & 11.50 & P value-0.009 \\
\hline
\end{tabular}

Table 4: Percentage of LSCS as per no of ANC visits

A statistically significant relationship was found between number of ANC visits \& number of LSCS performed. The increasing incidence of LSCS with the number of visits indicates complicated cases have high compliance rate.

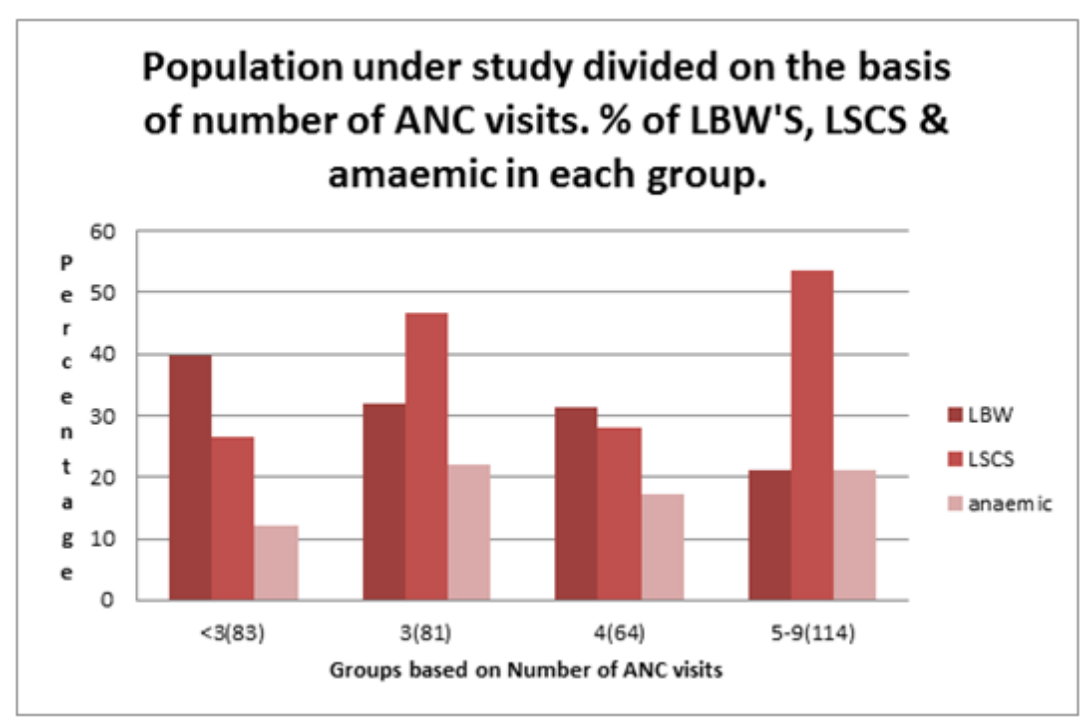




\begin{tabular}{|c|c|c|}
\hline No. of ANC visits & LBW & $\%$ \\
\hline$<3(83)$ & 33 & 39.75 \\
\hline $3(81)$ & 26 & 32.09 \\
\hline $4(64)$ & 20 & 31.25 \\
\hline $5-9(114)$ & 24 & 21.05 \\
\hline Total & 103 & 30.11 \\
\hline Chi square & 1.67 & P value- 0.64 \\
\hline
\end{tabular}

As seen in this table, a trend is seen, with increasing number ANC visits there is a decrease in LBW's but it was not statistically significant. So a further statistical analysis was done \& the number of ANC visits were divided into 2 groups $<5$ visits \& $\geq 5$ visits \& standard normal test for difference of population was applied.

\begin{tabular}{|c|c|c|c|}
\hline No. of ANC visits & N= population & LBW's & \% \\
\hline$<5$ & 228 & 79 & 34.64 \\
\hline$\geq 5$ & 114 & 24 & 21.05 \\
\hline & & $\mathrm{Z}=2.83$ & \\
\hline
\end{tabular}

Table 6: ANC visits and percentage of Low birth weight

Hence the number of LBW's were found to be significantly lowered by $14 \%$ in mothers who had visited the ANC clinic $\geq 5$ times as compared to mothers who has visited less than that.

\begin{tabular}{|c|c|c|}
\hline No. of ANC visits & anaemic & $\mathbf{\%}$ \\
\hline$<3(83)$ & 11 & 12.04 \\
\hline $3(81)$ & 18 & 22 \\
\hline $4(64)$ & 11 & 17.18 \\
\hline $5-9(114)$ & 11 & 21.05 \\
\hline Total & $\mathbf{5 1}$ & $\mathbf{1 4 . 9 1}$ \\
\hline Chi square & 5.3009 & P value-0.15 \\
\hline
\end{tabular}

Table 7: Correlation of ANC visits and anaemia

The increasing incidence of anaemia with number of visits appears to be paradoxical probably because of the complications has drawn more attention than anaemia.

Similar to the LBW's, they were too divided into 2 groups $<5 \& \geq 5$ visits \& standard normal test for difference of population were applied as shown below.

\begin{tabular}{|c|c|c|c|}
\hline No. of ANC visits & N= population & anaemic & \% \\
\hline$<5$ & 228 & 40 & 17.54 \\
\hline$\geq 5$ & 114 & 11 & 9.64 \\
\hline & & $\mathrm{Z}=2.24$ & \\
\hline
\end{tabular}

Table 8: Number of ANC visits and percentage of anaemia 
A statistical significance was found in the decrease in anaemic mothers who visited the Antenatal clinic $\geq 5$ times.

DISCUSSION: LBW poses many health problems to the newborn like increase in susceptibility to infections, slowing of physical as well as mental growth etc. Studies have also found some association between low birth weight \& future development of insulin resistance syndrome. 4

Our study has found a partially significant association between BMI \& LBW. It proved decrease in LBW with increase in BMI as shown in table 1.

Researches, on the contrary have found increase in LBW's with increase in BMI. ${ }^{5}$ This may be due to difference in population studied. In our study, as the population was from rural area, there weren't much obese women seen. So in the category of maximum BMI, were actually the properly nourished women. So increase in BMI signified good amount of nutrition \& thus decrease in LBW's.

Similarly the women who underwent LSCS were divided on the basis of the BMI. However, no association was found between the two as shown in table 2 . Again the studies ${ }^{6}$ were contradicted, which could be explained due to the difference in population studied, as mentioned above.

The anaemic mothers when divided in different BMI groups, a significant association was found between the two as shown in table 3 .

A significant association was found between number of ANC visits \& LSCS incidence. The study showed an increase in LSCS incidence with more number of ANC visits. The frequency of visits increases, if the female has some symptoms, ${ }^{6}$ of the complications, or if they are detected on regular checkup, she is advised more number of visits. The female visiting the clinic more has some complications which explain the increase in LSCS incidence rate.

As shown in the table 5, 6, 7, 8. A significant relationship was found between the number of ANC visit \&, LBW \& anaemia in pregnant female. Females with $\geq 5$ visits had lower rates of low birth weight babies \& anaemia at the time of delivery.

CONCLUSION: BMI is a good indicator of nutrition in pregnant women. Females with good BMI has less chances of having LBW baby \& have less chances of developing anaemia.

Good amount of antenatal care leads to decrease in maternal \& fetal mortality \& morbidity. Though a minimum number of 3 visits are suggested, the study proves, minimum number of 5 visits are essential to decrease the LBW \& anaemia incidence in mothers.

\section{BIBLIOGRAPHY:}

1. Height \& BMI: Who is at the risk for caesarean delivery? American Journal of Obstetrics \& gynaecology, Vol.195, issue 6, supplement 1, pg 201, Dec. 2006.

2. Maternal pre-pregnant BMI, maternal weight change \& off springs birth weight. Acta Obstetricia et gynaecologia Scandinavica. Vol.91, issue 2, pg 243-249, Feb 2012.

3. Preterm prediction study: association between maternal BMI \& spontaneous \& indicated preterm birth. American Journal of Obstetrics \& gynaecology. Vol. 192, issue3, pg 882, March 2005.

4. Effect of infant birth weight \& maternal body mass index in pregnancy on components of insulin resistance syndrome in China. American college of Physicians. Vol.132, no. 4, pg 253260. Feb. 152000. 
5. High Body Mass Index in Pregnancy, Its Effects on Maternal and Fetal Outcome Journal of Clinical Gynecology and Obstetrics. Volume 1, Number 1, February 2012, pages 15-18.

6. Association between Obesity during Pregnancy and Increased Use of Health Care. N Engl J Med 2008; April 3, 2008, 358:1444-1453.

\section{AUTHORS:}

1. Dattatraya Gopalghare

2. Renu Pimpale

3. Pranali Ghuge

4. Patit Paban Panigrahi

\section{PARTICULARS OF CONTRIBUTORS:}

1. Assistant Professor, Department of Obstetrics and Gynaecology, MIMER Medical College, Talegaon Dabhade, Pune.

2. Intern, Department of Obstetrics and Gynaecology, MIMER Medical College, Talegaon Dabhade, Pune.

3. Junior Resident, Department of Obstetrics and Gynaecology, MIMER Medical College, Talegaon Dabhade, Pune.
4. Professor and HOD, Department of Obstetrics and Gynaecology, MIMER Medical College, Talegaon Dabhade, Pune.

\section{NAME ADDRESS EMAIL ID OF THE CORRESPONDING AUTHOR:}

Dr. Dattatraya Gopalghare, D4-301, Latis Co-op Hsg Soc, Talegaon Chakan Road, Talegaon Dabhade, Talmaval District, Pune-410507.

Email: drgopalghare@yahoo.co.in

Date of Submission: 01/09/2014. Date of Peer Review: 02/09/2014. Date of Acceptance: 12/09/2014. Date of Publishing: 19/09/2014. 